\title{
Multi-parameter systematic strategy opinion that predicts, prevents, and personalized treats a cancer
}

\author{
Xianquan Zhan ${ }^{1,2,3,4^{*}}$, Rong $\mathrm{Hu}^{1,2,3}$, Xiaowei Wang ${ }^{1,2,3}$ \\ From EPMA-World Congress 2013 \\ Brussels, Belgium. 20-21 September 2013
}

Cancer is a complex whole-body disease that alters in the levels of gene, protein, and metabolite, and that involves multi-factors, multi-processes and multi-consequences. Individual variation is involved in each stage of prediction/prevention, early-stage diagnosis/therapy, and late-stage diagnosis/therapy. The development of omics and systems biology has promoted one to gradually change paradigms in oncology from traditional single factor strategy to multi-parameter systematic strategy. The therapeutic model of cancer has changed from the general radiotherapy and chemotherapy to personalized strategy. The development of PPPM will substantially change the understanding, prediction, prevention, and therapeutic model of cancer from a systematical and comprehensive point of view in the future.

\begin{abstract}
Authors' details
'Key Laboratory of Cancer Proteomics of Chinese Ministry of Health, Xiangya Hospital, Central South University, 87 Xiangya Road, Changsha, Hunan 410008 P. R. China. ${ }^{2}$ Hunan Engineering Laboratory for Structural Biology and Drug Design, Xiangya Hospital, Central South University, 87 Xiangya Road, Changsha, Hunan 410008 P. R. China. ${ }^{3}$ State Local Joint Engineering Laboratory for Anticancer Drugs, Xiangya Hospital, Central South University, 87 Xiangya Road, Changsha, Hunan 410008 P. R. China. ${ }^{4}$ The State Key Laboratory of Medical Genetics, Central South University, 88 Xiangya Road, Changsha, Hunan 410008 P. R. China.
\end{abstract}

Published: 11 February 2014

\section{References}

1. Hu R, Wang X, Zhan X: Multi-parameter systematic strategies for predictive, preventive and personalised medicine in cancer. EPMA J 2013, 4:2.

\footnotetext{
* Correspondence: yjzhan2011@gmail.com

${ }^{1}$ Key Laboratory of Cancer Proteomics of Chinese Ministry of Health, Xiangya Hospital, Central South University, 87 Xiangya Road, Changsha, Hunan 410008 P. R. China

Full list of author information is available at the end of the article
}

2. Zhan $X$, Desiderio DM: The use of variations in proteomes to predict, prevent, and personalize treatment for clinically nonfunctional pituitary adenomas. EPMA J 2010, 1:439-459.

3. Golubnitschaja O, Costigliola V, EPMA: General report \& recommendations in predictive, preventive and personalised medicine 2012: white paper of the European Association for Predictive, Preventive and Personalised Medicine. EPMA J 2012, 3:14.

\section{doi:10.1186/1878-5085-5-S1-A25}

Cite this article as: Zhan et al:: Multi-parameter systematic strategy opinion that predicts, prevents, and personalized treats a cancer. EPMA Journal 2014 5(Suppl 1):A25.
Submit your next manuscript to BioMed Central and take full advantage of:

- Convenient online submission

- Thorough peer review

- No space constraints or color figure charges

- Immediate publication on acceptance

- Inclusion in PubMed, CAS, Scopus and Google Scholar

- Research which is freely available for redistribution
C Biomed Central 